\title{
Avaliação da relação proteína-creatinina urinária em gatos com doença renal crônica ${ }^{1}$
}

\author{
Maria Cristina N. Castro ${ }^{*}$, Gracy C.G. Marcello ${ }^{3}$, Nayro X. Alencar ${ }^{2}$ e Ana \\ Maria R. Ferreira ${ }^{2}$
}

\begin{abstract}
Castro M.C.N., Marcello G.C.G., Alencar N.X. \& Ferreira A.M.R. 2009. [Urinary protein/creatinine ratio measurament in cats with chronic renal failure.] Avaliação da relação proteína-creatinina urinária em gatos com doença renal crônica. Pesquisa Veterinária Brasileira 29(8):605-609. Departamento de Patologia e Clínica Veterinária, Faculdade de Veterinária, Universidade Federal Fluminense, Rua Vital Brasil 64, Santa Rosa, Niterói, RJ 24230-340, Brazil. E-mail: mcnobre@vm.uff.br

Chronic renal disease (CRD) is the most common form of renal disease in cats. Several factors contribute to disease progression. Proteinuria is an important marker of renal disease progression. The protein-creatinine ratio in a single urine sample correlates well with urinary protein loss in 24 hours. The aim of this investigation was to determine the urine protein-creatinine (UPC) ratio in cats with natural acquired chronic renal disease. The UPC ratio was performed in nine clinically normal cats and in 30 cats with chronic renal disease. Mean UPC ratio in normal cats was $0.16 \pm 0.10$, and mean UPC ratio in the cats with chronic renal disease was $0.53 \pm 0.59$. In the group with renal disease there was positive correlation between UPC ratio and serum creatinine levels. The results obtained from this study demonstrate that UPC ratio in cats with CRD is variable and that, in accordance to what has previously been described, approximately one third of the cats with CRD are considered proteinuric according to the criteria established in literature (UPC ratio > 0.4).
\end{abstract}

INDEX TERMS: Diseases of cats, chronic renal disease, urinary protein/creatinine ratio.

RESUMO.- Doença renal crônica (DRC) é a forma mais comum de doença renal em gatos. Vários fatores têm sido citados como importantes na progressão da doença, dentre eles a proteinúria. A relação proteína-creatinina (RPC) urinária em uma única amostra de urina apresenta boa correlação com a perda de proteína urinária em 24 horas. O objetivo dessa investigação foi determinar a RPC urinária em gatos com DRC adquirida naturalmente. A determinação da RPC foi realizada em nove gatos saudáveis (Grupo I) e em trinta gatos com DRC (Grupo II). Os gatos do Grupo I apresentaram RPC de 0,16 $\pm 0,10$ e os gatos do Grupo II apresentaram RPC de 0,53 0,59.

\footnotetext{
${ }^{1}$ Recebido em 31 de dezembro de 2008.

Aceito para publicação em 19 fevereiro de 2009.

2 Departamento de Patologia e Clínica Veterinária, Faculdade de Veterinária, Universidade Federal Fluminense (UFF), Rua Vital Brasil 64, Santa Rosa, Niterói, RJ 24230-340, Brasil. *Autor para correspondência: mcnobre@vm.uff.br

${ }^{3}$ Curso de Pós-graduação, Faculdade de Veterinária, UFF, Niterói, RJ.
}

No Grupo Il encontrou-se correlação positiva e significante da RPC com o nível de creatinina sérica. Os resultados deste estudo demonstram que a RPC urinária em gatos com DRC é bastante variável e que, à semelhança do que já havia sido previamente descrito, aproximadamente um terço dos gatos com DRC são considerados proteinúricos segundo critérios estabelecidos pela literatura (RPC urinária $>0,4$ ).

TERMOS DE INDEXAÇÃO: Doenças de gatos, doença renal crônica, relação proteína-creatinina urinária.

\section{INTRODUÇÃO}

A doença renal crônica ( $D R C$ ) é comumente diagnosticada em gatos e é uma causa importante de morte nessa espécie (Richards et al. 2005). Quando mais de $75 \%$ da massa funcional renal é perdida, caracteriza-se a insuficiência renal (Polzin et al. 2005). A causa primária da DRC geralmente não é identificada no momento do diagnóstico e muitos fatores podem estar envolvidos com a pro- 
gressão da doença para o estágio terminal (Elliot \& Barber 1998), inclusive os próprios mecanismos compensatórios que o organismo apresenta para a manutenção da homeostase. O conhecimento desses fatores é importante, uma vez que na terapia a ser instituída objetiva-se eliminar ou minimizar seus efeitos deletérios.

Uma das conseqüências da perda progressiva dos néfrons na DRC é o aumento da filtração glomerular. Essa hiperfiltração leva à esclerose glomerular e proteinúria (Brenner et al. 1996). A proteinúria tem sido considerada um importante fator na progressão da DRC em humanos (Willians et al. 1988), em cães (Jacob et al. 2005) e em gatos (Syme et al. 2006).

A urina de cães e gatos normais possui pequena quantidade de albumina e outras proteínas. A permeabilidade seletiva da membrana basal glomerular restringe a filtração da maior parte das proteínas plasmáticas, o que leva à filtração apenas de proteínas com baixo peso molecular e daquelas com carga elétrica neutra ou positiva. As células epiteliais do túbulo proximal são capazes de promover a reabsorção ativa, por endocitose, de muitas proteínas provenientes do filtrado glomerular (Grauer 2007).

Estudos têm demonstrado que a excreção diária normal de proteína na urina de cães e gatos é de, no máximo, $10-30 \mathrm{mg} / \mathrm{kg}$ (Grauer 2007). A coleta total da urina produzida em 24 horas para determinação da quantidade de proteína perdida, um exame freqüentemente utilizado em medicina humana, é inviável na rotina de atendimento clínico, pois há necessidade do uso de gaiolas metabólicas ou cateterizações prolongadas (White et al. 1984). Estudos demonstram que a medida obtida de uma única amostra de urina para determinação da relação proteína-creatinina (RPC) urinária apresenta boa correlação com a determinação da proteína perdida em 24 horas em cães (White et al. 1984, Ruggeneti et al. 1998), gatos (Monroe et al. 1989, Adams et al. 1992) e humanos (Nell \& Grinden 2000).

A creatinina é considerada um bom indicador da estimativa da taxa de filtração glomerular e, conseqüentemente, a concentração urinária de creatinina é proporcional à concentração total de soluto na urina. Logo, quando a taxa de creatinina excretada na urina é comparada com a quantidade de proteína urinária através da RPC, a quantidade de proteína perdida pode ser quantificada, eliminando-se a interferência do volume de urina (Finco 1995, Brunker 2005). Atualmente discute-se sobre qual nível de proteinúria deve ser considerado normal e qual nível poderá estar relacionado com a progressão da doença renal em cães e gatos (Grauer 2007).

O objetivo deste estudo foi determinar a RPC urinária em gatos com doença renal crônica naturalmente adquirida.

\section{MATERIAL E MÉTODOS}

Foram incluídos neste estudo 39 gatos divididos em dois grupos: Grupo I (controle [nove gatos]) e Grupo II (DRC [30 gatos]). Todos os gatos do grupo controle foram atendidos em consulta geriátrica e, após exame físico e análise dos resulta- dos de exames laboratoriais (hemograma, urinálise e dosagem sérica de uréia e creatinina), foram considerados saudáveis. A coleta da urina foi realizada por cistocentese em quatro gatos e por micção espontânea em cinco gatos.

Para inclusão no Grupo II, foram avaliados 30 gatos com diagnóstico de DRC realizado após exame físico e análise dos resultados de exames laboratoriais (hemograma, urinálise e dosagem sérica de uréia e creatinina). A coleta da urina foi realizada por cistocentese em 18 gatos e por micção espontânea em 12 gatos. Foi coletado uma quantidade mínima de $5 \mathrm{~mL}$ de urina.

Em todos os gatos foi coletado aproximadamente $5 \mathrm{~mL}$ de sangue por punção das veias cefálica ou femoral após jejum de 12 horas; $2 \mathrm{~mL}$ para realização do hemograma e $3 \mathrm{~mL}$ para dosagens bioquímicas.

Após a coleta da urina, foi realizada a urinálise e $1 \mathrm{~mL}$ da amostra foi centrifugado a $1.500 \mathrm{rpm}$, por cinco minutos e o volume do sobrenadante obtido foi congelado a $-20^{\circ} \mathrm{C}$ em microtubos para as dosagens bioquímicas de proteína e creatinina.

Para as dosagens de proteína e creatinina urinárias utilizouse o analisador bioquímico semi-automático ${ }^{4}$. A dosagem de proteína na urina foi realizada utilizando-se kit comercial ${ }^{5}$, que se fundamenta no princípio do vermelho de pirogalol, em reação de ponto final e leitura em comprimento de onda de 620nm. A dosagem de creatinina urinária foi realizada com o princípio de Jaffé picrato alcalino, utilizando-se o kit comercial $^{6}$ em reação de ponto final e leitura em comprimento de onda de 505nm. Para essa dosagem as amostras de urina foram diluídas na proporção de 1:20 em água destilada para atingir a faixa de linearidade do teste e o valor final foi devidamente corrigido. A RPC foi obtida calculando-se a razão entre o valor de proteína e o de creatinina, ambas expressas na mesma unidade (mg/dL).

Índices de RPC urinária menores que 0,4 em gatos são utilizados como valores de normalidade (Lees et al. 2005, Grauer 2007), porém para melhor interpretação desse parâmetro de diagnóstico nos paciente com DRC, também utilizamos a classificação proposta pela Sociedade Internacional de Interesse em Rim (IRIS), na qual gatos com resultados da $\mathrm{RPC}<0,2$ são categorizados como não-proteinúricos, de 0,2-0,4 são considerados suspeitos e $>0,4$ são considerados proteinúricos (Syme et al. 2006).

A análise dos resultados foi realizada com o programa estatístico comercial $^{7}$ e os resultados apresentados em média e desvio padrão. Os índices de correlação foram determinados pelo teste de Pearson. $O$ valor $p<0,05$ foi utilizado para definir significância estatística.

\section{RESULTADOS}

Os nove gatos incluídos no Grupo I eram castrados, tinham idades que variavam entre oito e 14 anos $(11,44 \pm 2,35)$ e peso entre 2,3 e $5,0 \mathrm{~kg}(3,4 \pm 0,74)$. Destes, sete eram fêmeas e dois eram machos; dois eram da raça Siamês e sete não tinham raça definida.

\footnotetext{
${ }^{4}$ Bio $200 L \Theta$, Bioplus Produtos para Laboratório Ltda, Estrada Dr. Cícero Borges de Moraes 1701, Vila Nova, Barueri, SP.

${ }^{5}$ Sensiprot $囚$, Labtest Diagnóstica SA, Av. Paulo Ferreira da Costa 600, Lagoa Santa, MG.

${ }^{6}$ Creatinina $\circledast$, Labtest Diagnóstica SA, Av. Paulo Ferreira da Costa 600, Lagoa Santa, MG.

${ }^{7}$ SigmaStat $^{\mathrm{TM}}$, Jandel Scientific Corporation, San Raphael, CA, Estados Unidos.
} 


\begin{tabular}{|c|c|c|c|c|c|}
\hline & Grupo I & Grupo II & $\begin{array}{c}\text { Grupo II } \\
\text { RPC }<0,2\end{array}$ & $\begin{array}{c}\text { Grupo II } \\
\text { RPC } 0,2-0,4\end{array}$ & $\begin{array}{c}\text { Grupo II } \\
\text { RPC }>0,4\end{array}$ \\
\hline Número de gatos & $\mathrm{n}=9$ & $\mathrm{n}=30$ & $\mathrm{n}=13$ & $n=6$ & $\mathrm{n}=11$ \\
\hline Creatinina $^{1}$ & $1,23 \pm 0,14$ & $3,3 \pm 1,5$ & $3,05 \pm 1,05$ & $3,17 \pm 1,53$ & $3,68 \pm 1,94$ \\
\hline Uréia $^{1}$ & $51 \pm 10,8$ & $145,5 \pm 78,5$ & $124,23 \pm 65,67$ & $138,0 \pm 46,95$ & $174,62 \pm 80,14$ \\
\hline RPC urinária & $0,16 \pm 0,10$ & $0,53 \pm 0,59$ & $0,11 \pm 0,0032$ & $0,32 \pm 0,0085$ & $1,11 \pm 0,63$ \\
\hline
\end{tabular}

${ }^{1} \mathrm{mg} / \mathrm{dL}$.

Os 30 gatos incluídos no Grupo II tinham idades que variavam entre oito e 25 anos $(13,33 \pm 4,42)$ e peso entre 1,4 e $6,0 \mathrm{~kg}(3,4 \pm 1,26)$. Destes, 17 eram machos $(56,7 \%)$ e 13 eram fêmeas (43,3\%); 23 eram castrados $(76,7 \%)$ e sete eram inteiros $(23,3 \%) ; 24$ não tinham raça definida $(80,0 \%)$, quatro eram da raça Siamês $(13,3 \%)$, um era Persa $(3,3 \%)$ e um era British Short Hair $(3,3 \%)$.

Os resultados, de ambos os grupos, dos níveis séricos de uréia e creatinina e da RPC urinária em média e desvio padrão podem ser contemplados no Quadro 1.

No Grupo I, sete gatos apresentaram densidade urinária maior que 1,040, um gato apresentou densidade urinária de 1,038 e outro apresentou densidade de 1,034. No Grupo II, os gatos apresentaram densidade urinária média de $1,016 \pm 0,01$. As análises dos sedimentos urinários de todos os gatos, independentemente do grupo, não apresentaram alterações sugestivas de inflamação do trato urinário (sedimento inativo).

A correlação da RPC com os índices de creatinina nos gatos do Grupo Il foi positiva (índice de correlação $=0,41$ ) e significante $(p=0,022)$. A correlação da RPC com a uréia sérica foi positiva (índice de correlação $=0,34$ ) e não significante $(p=0,063)$.

\section{DISCUSSÃO E CONCLUSÕES}

A urina dos gatos do Grupo I apresentou RPC de $0,16 \pm 0,10$. Os primeiros estudos (Monroe et al. 1989) realizados para determinação da quantidade normal de proteína na urina de gatos, encontrou a RPC de $\leq 0,7$. Outro estudo (Adams et al. 1992), realizado posteriormente, encontrou a RPC de 0,13 $\pm 0,04$. Mais recentemente, um estudo (Syme et al. 2006) encontrou o valor a RPC de 0,15 . Assim, os resultados encontrados por nós para o Grupo I estão de acordo com a literatura mais recente.

A densidade urinária de $1,016 \pm 0,01$ encontrada no Grupo II comprova a incapacidade de concentração urinária observada em gatos com DRC e é semelhante à descrita por outros autores em estudos anteriores ( $\mathrm{Di}$ Bartola et al. 1987, Elliot et al.1998, Syme et al. 2006, King et al. 2007). A avaliação microscópica do sedimento urinário não identificou alterações sugestivas de inflamação que levassem à possibilidade do diagnóstico de proteinúria pós-renal (Biewenga 1982, Grant \& Forrester 2001, Santos et al. 2001).

Os gatos do Grupo II apresentaram RPC de 0,53 $\pm 0,59$. Esses valores são semelhantes àqueles reportados em um estudo recente (King et al. 2007) realizado com 190 gatos com DRC. Nesse estudo, os autores encontraram uma RPC de $0,4 \pm 0,8$. Ambos os estudos demonstraram resultados superiores aos encontrados em gatos com DRC cirurgicamente induzida, na qual a RPC foi de $0,36 \pm 0,37$ (Adams et al. 1992).

Considerando-se o estadiamento proposto pela IRIS no que concerne ao grau de proteinúria, $13(43,3 \%)$ gatos do Grupo II apresentaram RPC $<0,2$, e foram considerados não-proteinúricos. Esses resultados são semelhantes ao observados por outros autores (Syme et al. 2006, King et al. 2007) que encontraram $49 \%$ e $66,6 \%$ dos gatos com DRC apresentando RPC $<0,25$ e $<0,2$, respectivamente. Seis $(20 \%)$ gatos desse grupo apresentaram RPC entre 0,2 e 0,4, ou seja, são gatos que apresentaram proteinúria em valores considerados limítrofes. Apesar da maior proporção $(63,3 \%)$ dos gatos ter apresentado resultados dentro do atual valor de referência de normalidade proposto para RPC para a espécie $(<0,4)$, é importante ressaltar que em estudo recente (King et al. 2007) foi demonstrado que valores tão baixos como 0,2 podem ser clinicamente relevantes e que quanto maior a RPC menor o tempo de sobrevida do gato. Portanto, ao incluirmos os gatos por nós estudados com RPC acima de 0,2 como proteinúricos, registramos mais da metade do grupo nessa categoria. É importante essa avaliação, pois a determinação dos valores de normalidade tende a mudar à medida que as alterações que ocorrem na DRC adquirida vão sendo conhecidas, o que permitirá a introdução de condutas terapêuticas de forma mais precoce.

Onze gatos (36,7\%) apresentaram RPC superior a 0,4, o que caracteriza perda urinária mais grave. Porém, apenas cinco $(16,7 \%)$ apresentaram RPC $>1$, proporção próxima à encontrada em dois diferentes estudos (Syme et al. 2006, King et al. 2007) que reportaram apenas $10 \%$ dos gatos com DRC apresentando RPC $>1$. Segundo outro autor (Grauer 2007), esse índice de proteinúria é considerado grave e geralmente está associado à glomerulonefrite, sendo mais comumente encontrado em cães e também reportado no homem (Remuzzi \& Bertani 1998). Nos gatos com DRC a lesão tubulointersticial é a alteração histopatológica mais comumente observada (DiBartola et al. 1987, Syme et al. 2006). Mesmo não sendo comum, valores de RPC $>1$ poderão ocorrer em gatos, geralmente naqueles em falência renal progressiva próxima ao estágio terminal (Lees et al. 2005, Kuwahara et al. 2006). 
Analisando-se a correlação da RPC com os índices de uréia e creatinina nos gatos estudados encontramos uma correlação positiva e significante $(p<0,05)$ apenas com a creatinina sérica. Esse resultado é semelhante àquele encontrado por outros autores (Syme et al. 2006) em um estudo anterior, mas diferentes dos observados em outro estudo recente (King et al. 2007), no qual, apesar de não ter sido encontrada a correlação aqui demonstrada, tanto a creatinina como a RPC foram considerados fatores independentes de risco para menor sobrevida de gatos com DRC. Estudos anteriores já relataram uma associação positiva da RPC com o grau de azotemia em gatos com DRC (Elliot \& Barber 1998). Em humanos, o grau de proteinúria e de creatinina sérica foram considerados os melhores parâmetros testados para determinação do risco de falência renal terminal (Shahinfar et al. 2005) e a proteinúria foi incriminada como o principal fator de progressão da DRC em pacientes diabéticos (Keane et al. 2003). Também em cães com DRC, a proteinúria é considerada um fator prognóstico importante (Jacob et al. 2005).

Os resultados deste estudo demonstram que a RPC urinária em gatos com DRC é bastante variável e que, à semelhança do que já havia sido previamente descrito, aproximadamente um terço dos gatos com DRC são considerados proteinúricos segundo critérios estabelecidos pela IRIS (RPC urinária $>0,4$ ). Quando gatos com RPC urinária entre 0,2 e 0,4 (suspeitos de proteinúria segundo os critérios da IRIS) são incluídos como proteinúricos, essa ocorrência ultrapassa $50 \%$ dos casos.

\section{REFERÊNCIAS}

Adams L.G., Polzin D.J., Osborne C.A. \& O’Brien T.D. 1992. Correlation of urine protein/creatinine ratio and twenty-four-hour urinary protein excretion in normal cats and cats with surgically induced chronic renal failure. J. Vet. Intern. Med. 6:36-40.

Bastos M.G., Carmo W.B., Abrita R.R., Almeida E.C., Mafra D., Castro D.M.N., Oliveira L.A., Santos F.R., Gonçalves J.A. \& Paula R.B. 2004. Doença renal crônica: problemas e soluções. J. Bras. Nefrol. 26:202215.

Biewenga W.J., Gruys E.H. \& Hendriks J. 1982. Urinary protein loss in the dog: Nephrological study of 29 dogs without signs of renal disease. Res. Vet. Sci. 33:366-374.

Brenner B.M., Lawler E.V. \& Mackenzie H.S. 1996. The hyperfiltration theory: A paradigm shift in nephrology. Kidney Int. 49:1774-1777.

Brown S.A. \& Brown C.A. 1995. Single-nephron adaptations to parcial renal ablation in cats. Am. J. Physiol. 269:1002-1008.

Brunker J. 2005. Protein losing nephropaty. Comp. Cont. Educ. Pract. Vet. 27:686-695.

DiBartola S.P., Rutgers H.C., Zack P.M. \& Tarr M.J. 1987. Clinicopathologic findings associated with chronic renal disease in cats: 74 cases (19731984). J. Am. Vet. Med. Assoc. 190:1196-1202.

Elliot J. 2000. Cómo prolongar la vida del paciente felino con insuficiencia renal. Waltham Focus 10:10-14.

Elliot J. \& Barber P.J. 1998. Feline chronic renal failure: Clinical findings in 80 cases diagnosed between 1992-1995. J. Small Anim. Pract. 39:78-85.

Finco D. 1995. Urinary protein loss, p.211-215. In: Osborne C.A. \& Fin- co D.R. (Eds) Canine and Feline Nephrology and Urology. Lea and Febiger, Baltimore. 960p.

Grant D.C. \& Forrester S.D. 2001. Glomerulonephritis in dogs and cats: Diagnosis and treatment. Comp. Cont. Educ. Pract. Vet. 23:798-804.

Grauer G.F. 2007. Measurement, interpretation, and implications of proteinuria and albuminuria. Vet. Clin. North Am., Small Anim. Pract. 37:283-295

Hebert L.A., Wilmer W.A., Falkenhain M.E., Wofford S., Nahman S. \& Rovin B.H. 2001. Renoprotection: One or many therapies? Kidney Int. 59:1211-1226.

Jacob F., Polzin D.J., Osborne C.A., Neaton J.D., Kirk C., Allen T. \& Swanson L.L. 2005. Evaluation of the association between initial proteinuria and morbidity rate or death in dogs with naturally occurring chronic renal failure. J. Am. Vet. Med. Assoc. 226:393-400.

Jafar T.H., Stark P.C., Schmid H., Landa M., Maschio G., Marcantoni C., Jong P., Zeeuw D., Shahinfar S., Ruggenenti P., Remuzzi G. \& Levey A. 2001. Proteinuria as a modifiable risk factor for the progression of non-diabetic renal disease. Kidney Int. 60:1131-1140.

Keane W.F., Brenner B., Zeeuw D., Grunfeld J., McGill J., Mrrch W., Ribeiro A., Shahinfar S., Simpson R., Snapinn S. \& Totto R. 2003. The risk of developing end-stage renal disease in patients with type 2 diabetes and nephropaty: The renal study. Kidney Int. 63:1499-1507.

King J.N., Tasker S., Gunn-Moore D. \& Strehlau G. 2007. Prognostic factors in cats with chronic kidney disease. J. Vet. Intern. Med. 21: 906-916.

Kuwahara Y., Ohba Y., Kitoh K., Kuwahara N. \& Kitagawa H. 2006. Association of laboratory data and death within one month in cats with chronic renal failure. J. Small Anim. Pract. 47:446-450.

Lees G. 2004. Early diagnosis of renal disease and renal failure. Vet. Clin. North Am., Small Anim. Pract. 34:867-885.

Lees G., Brown S., Elliot J., Grauer G.F. \& Vaden S.L. 2005. Assessment and management of proteinuria in dogs and cats. J. Vet. Intern. Med. 19:377-385.

Lulich J.P. \& Osborne C.A.1990. Interpretation of urine protein-creatinine ratios in dogs with glomerular and nonglomerular disorders. Comp. Cont. Educ. Pract. Vet 12:59-73.

Monroe W.E., Davenport D. \& Saunders G.K. 1989. Twenty-four hour urinary loss in healthy cats and the urinary protein-creatinine ratio as an estimate. Am. J. Vet. Res. 50:1906-1909.

Neel J.A. \& Grindem C.B. 2000. Understanding and evaluating renal function. Vet. Med. 95:555-565.

Plotnick A. 2007. Feline chronic renal failure: Long-term medical management. Comp. Cont. Educ. Pract. Vet. 29(6):342-350.

Polzin D.J., Osborne C.A. \& Ross C.A. 2005. Chronic renal disease, p.1756-1785. In: Ettinger S.J. \& Feldman E. (Eds), Textbook of Veterinary Internal Medicine. 6th ed. W.B. Saunders, Philadelphia. 2208p.

Remuzzi G. \& Bertani T. 1998. Pathophysiology of progressive nephropathies. N. Engl. J. Med. 339(20):1448-1456.

Richards J.R., Rodan I., Beekman G.K., Carlson M.E., Graves T.K., Kent E.M., Landdsberg G.M., Pittari J.M. \& Wolf A.M. 2005. Panel report on feline senior care. J. Feline Med. Surg. 7(1):3-32.

Ruggeneti P., Gasparini F., Perna A. \& Remuzzi G. 1998. Cross sectional longitudinal study of spot morning urine protein: Creatinine ratio, 24 hour urine protein excretion rate, glomerular filtration rate, and end stage renal failure in chronic disease in patients without diabetes. Brit. Med. J. 316:504-509.

Ruggeneti P., Gasparini F., Perna A. \& Remuzzi G. 2003. Retarding progression of chronic renal disease: The neglected issue of residual proteinuria. Kidney Int. 63:2254-2261. 
Santos A.M.R., Lemos C.C.S. \& Bregman R. 2001. Revisão: proteinúria, marcador clássico de comprometimento glomerular. J. Bras. Nefrol. 23:217-20.

Shahinfar S., Dickson T., Zhang Z., Keane W.F. \& Brenner B.M. 2005. Baselines predictors of end-stage renal risk in patients with type 2 diabetes and nephropathy: New lessons from the renal study. Kidney Int. 67:S48-S51.

Syme H.M., Markwell D.P. \& Elliot J. 2006. Survival of cats with naturally occurring chronic renal failure is related to severity of proteinuria. $\mathrm{J}$. Vet. Intern. Med. 20:528-535.

White J.V., Olivier N.B., Reimann K. \& Johnson C. 1984. Use of proteinto-creatinine ratio in a single specimen for quantitative estimation of canine proteinuria. J. Am. Vet. Med. Assoc. 185:882-885.

Willians P.S., Fass G. \& Bone J.M. 1988. Renal pathology and proteinuria determine progression in unrelated mild/moderate chronic renal failure. Q. J. Med. 67:343-354. 